\title{
Rain Cracking in Sweet Cherries is not Due to Excess Water Uptake but to Localized Skin Phenomena
}

\author{
Andreas Winkler, Stefanie Peschel, Kathleen Kohrs, and Moritz Knoche ${ }^{1}$ \\ Institute for Horticultural Production Systems, Leibniz-University Hannover, Herrenhäuser Straße 2, \\ 30419 Hannover, Germany
}

Additional IndeX words. Prunus avium, perfusor, splitting, strain, turgor

\begin{abstract}
Rain cracking of sweet cherry (Prunus avium L.) fruit is commonly thought to result from excessive net water uptake. This excess increases flesh turgor, which then strains and eventually ruptures the skin at the weakest point. This idea - the critical turgor hypothesis-assumes the fruit comprises a semifluid flesh, held under pressure by a taut skin. The objectives of this study were to test the validity of this popular hypothesis. We investigated the effects of 1) the different pathways of water uptake and 2) the fruit's water balance on cracking. Incubating fruit of 19 cultivars in water resulted in rapid fruit cracking. The time to $50 \%$ cracking $\left(T_{50}\right)$ averaged $7.5 \pm 1.3$ hours with considerable variability between cultivars $\left(T_{50}\right.$ range from 1.5 to 18.6 hours). The amount of water taken up at $50 \%$ cracking $\left(\mathrm{WU}_{50}\right)$ averaged $96.5 \pm 17.6 \mathrm{mg}\left(\mathrm{WU}_{50}\right.$ range from 17.7 to $\left.331.5 \mathrm{mg}\right)$. There was no correlation between either the $T_{50}$ or the $W_{U_{50}}$, and the rate of water uptake. Also, there was no correlation between the values of $T_{50}$ $(r=0.58)$ and only a weak correlation between the values of $\mathrm{WU}_{50}\left(r=0.80^{*}\right)$ determined in different years. Comparing the value of $\mathrm{WU}_{50}$ under incubation vs. under perfusion revealed a 3.9- to 38-fold higher $\mathrm{WU}_{50}$ under perfusion (397.6 to $1840 \mathrm{mg}$ ) than under incubation $(48.8$ to $102.6 \mathrm{mg})$. This marked dissimilarity remained, regardless of pretreatments with isotonic polyethylene glycol (PEG) 6000 to induce microcracking or by manipulation of skin wetness during perfusion. Sealing the pedicel/fruit junction markedly decreased the rate of water uptake under incubation. It had no effect on the $T_{50}$, and it markedly decreased the $\mathbf{W U}_{50}$. Similarly, manually induced skin defects greatly increased the rate of water uptake but, with few exceptions, had no effect on the $T_{50}$, whereas, the $W_{50}$ had increased. The location on the fruit surface of the resulting cracks was not related to the region of the skin in which the manual defect was induced. Allowing the fruit to transpire increased both, the $T_{50}$ and the $\mathrm{WU}_{50}$. Interestingly, the amount of water lost by transpiration exceeded the amount that was subsequently required to cause cracking up to 5-fold. Incubating fruit with their stylar ends immersed in water, whereas their remaining surfaces were in air of $0 \%$, $\mathbf{2 8 \%}, \mathbf{7 5 \%}$, or $100 \%$ relative humidity $(\mathrm{RH})$ resulted in net losses of water of up to $5.9 \pm 0.7 \mathrm{mg} \cdot \mathrm{h}^{-1}$, nevertheless their stylar ends still cracked. All our results indicate rain cracking in sweet cherries is a localized phenomenon that is not related to the net fruit water balance (the critical turgor hypothesis) but is the result of more local exposure of the fruit skin to liquid-phase water (the zipper hypothesis).
\end{abstract}

Rain cracking severely limits sweet cherry production in all regions of the world where rainfall occurs immediately before and during the harvest period (Christensen, 1996). Rain cracking is thought to be related to an excessively positive water balance resulting from 1) uptake of surface water through the fruit skin (Christensen, 1996), 2) via the vasculature of the pedicel (Measham et al., 2010; Sekse et al., 2005), and coupled with 3) the much-reduced transpiration of a wet fruit under humid conditions (Knoche and Measham, 2016).

A commonly cited model of rain cracking of soft and fleshy fruit is the critical turgor model originally proposed by Considine and Kriedemann (1972) for grape (Vitis vinifera L.) berries. This concept assumes the flesh of the berry to be held under compression by an elastically strained skin. Upon water uptake, the pressure in the fruit rises. When the fruit pressure (synonymous with fruit turgor and with flesh turgor) exceeds some critical threshold; i.e., the critical turgor pressure, the fruit skin is strained beyond its limit of extensibility and it cracks (Considine and Kriedemann, 1972). Although developed

Received for publication 23 Sept. 2016. Accepted for publication 31 Oct. 2016. This research was funded in part by a grant from the Deutsche Forschungsgemeinschaft.

We thank Dieter Reese for designing and building the perfusor, Friederike Schroeder, Simon Sitzenstock, and Matthias Hinz for technical support, and Sandy Lang and Martin Brüggenwirth for helpful comments on an earlier version of this manuscript.

${ }^{1}$ Corresponding author. E-mail: moritz.knoche@obst.uni-hannover.de. for grapes, the critical turgor model has also been used to account for rain cracking in sweet cherries (Measham et al., 2009; Sekse, 1995a, 1998a; Sekse et al., 2005). This is not unreasonable, given the similar sizes, shapes, textures, and external architectures of grapes and sweet cherries (notwithstanding the multiple small seeds of the one and the single large pit of the other).

The critical turgor model offers a logical conceptual framework for discussion of rain cracking in sweet cherry, which is consistent with the following empirical and experimental observations: 1) Sweet cherry fruit comprise two distinct tissues - the flesh and the skin. There is no published evidence (of which we are aware) that suggests the pit plays any role in cracking. The cellular components of the skin form the load-bearing structure implied in the critical turgor model (Brüggenwirth et al., 2014). 2) The sweet cherry skin is markedly strained (Grimm et al., 2012; Knoche et al., 2004). A portion of this strain is elastic (Brüggenwirth et al., 2014). According to Hook's law, elastic strain is caused by a proportional stress and this (in a near spherical fruit) can be simply related to a biaxial strain and a proportional internal pressure. 3) Rain cracking is reported to be affected by irrigation (Sekse, 1995b) and also occurs occasionally in fruit grown under rain shelters. These observations suggest water uptake can occur along different parallel pathways - e.g., both via vascular sap flow (xylem and phloem) in the pedicel and also via surface water uptake through a wet skin (osmotic uptake) - both of these pathways potentially contributing to rain cracking 
(Cline et al., 1995). 4) Conversely, skin cracking is markedly decreased if surface water uptake is decreased, e.g., by incubating fruit in aqueous $\mathrm{FeCl}_{3}$ (Beyer et al., 2002; Weichert et al., 2004). Whereas the above observations are consistent with the critical turgor model (Considine and Kriedemann, 1972), the low turgor pressure recently reported in mature sweet cherry and-in particular-the lack of response of turgor to water uptake and transpiration (Knoche et al., 2014; Schumann et al., 2014) are not consistent with the critical turgor model.

The objective of the present study was to test the validity of the critical turgor model for sweet cherry rain cracking. We specifically investigated the effects of the route of water uptake and of the fruit's water balance on cracking. The pathway of water uptake was varied by 1) perfusing sweet cherry fruit; 2) by inducing microcracking and surface defects as parallel pathways for water uptake; and 3) by sealing the pedicel/fruit junction. The fruit's water balance was varied by allowing whole fruit or selected regions of the fruit surface to transpire before conducting cracking assays.

\section{Material and methods}

Plant material. Mature sweet cherry fruit of the cultivars Burlat and Summit for the perfusion experiments were harvested from a commercial orchard near Höhnstedt, Germany (lat. $51^{\circ} 30^{\prime} \mathrm{N}$, long. $11^{\circ} 44^{\prime} \mathrm{E}$ ) and from an experimental orchard in Marquardt, Germany (lat. $52^{\circ} 31^{\prime} \mathrm{N}$, long. $12^{\circ} 51^{\prime} \mathrm{E}$; Bundessortenamt, Prüfstelle Marquardt). Fruit used for the cracking assays (i.e., of the cultivars Adriana, Burlat, Dönissens Gelbe, Earlise, Early Korvic, Fabiola, Flamengo Srim, Gill Peck, Hedelfinger, Kordia, Merchant, Querfurther Königskirsche, Rainier, Regina, Sam, Samba, Schneiders Späte Knorpel, Staccato, and Sweetheart) were from greenhouse grown or field-grown trees at the Horticultural Research Station of the Leibniz University in Ruthe, Germany (lat. $52^{\circ} 14^{\prime} \mathrm{N}$, long. $\left.9^{\circ} 49^{\prime} \mathrm{E}\right)$. Most cultivars were grafted on 'Gisela 5' rootstocks (Prunus cerasus L. $\times$ Prunus canescens Bois). The only exceptions were 'Burlat' and 'Summit' used in the perfusion experiments. These two cultivars were grafted on 'Mazzard' ( $P$. avium). Fruit of uniform size and color without visible defects were selected at commercial maturity from a minimum of three trees per cultivar. Unless specified otherwise, the pedicels were cut flush with the receptacle and the pedicel end, the receptacle and the pedicel/fruit junction were sealed with silicone rubber (3140 RTV coating; Dow Corning, Midland, MI). The silicone rubber was allowed to cure overnight. This procedure limited fruit water uptake to the skin surface only. Preliminary experiments established that holding fruit overnight at $2{ }^{\circ} \mathrm{C}$ had no effect on water uptake and cracking (A. Winkler, unpublished data).

INTRINSIC CRACKING TEST. Unless otherwise specified, the intrinsic cracking susceptibility was determined as described by Weichert et al. (2004) and Winkler et al. (2015). Briefly, two groups of 25 fruit each were incubated in deionized water. Fruit were removed from the water at regular intervals and checked for macroscopically visible skin cracks. Cracked fruits were removed and noncracked fruits were reincubated in water. Water uptake was determined gravimetrically in a separate experiment on fruit from the same batch. Fruits were weighed, incubated in deionized water, removed after 45 and $90 \mathrm{~min}$, blotted with tissue paper, reweighed, and reincubated. The rate of water uptake was calculated on an individual fruit basis as the slope of a linear regression fitted through a plot of cumulative fruit mass vs. time. The number of individual fruit replicates was 15 . From these data, the time to $50 \%$ cracking and the amount of water uptake at 50\% cracking were calculated (Winkler et al., 2015).

Perfusion Test. In the perfusion assays, a fruit was perfused through a hypodermic needle inserted through a silicone rubber septum that covered the receptacle and sealed the pedicel/fruit junction (for a sketch see Lang and Düring, 1990). The needle was positioned such that the tip was close to the pit on the cheek of the fruit. The custom built perfusor comprised a total of 30 disposable syringes connected via rigid polytetrafluoroethylene tubing to the hypodermic needles inserted in the fruit. The rate of perfusion was $44.9 \mathrm{mg} \cdot \mathrm{min}^{-1}$. Fruit was perfused at ambient temperature up to the point of cracking. At this time, the volume injected into the fruit was read from the syringe. Cracking was assessed by visual inspection. Preliminary experiments established that it was technically impossible to perfuse sweet cherry fruit through the vascular system of the pedicel, probably because of the high hydraulic resistance of the vasculature within the fruit (Brüggenwirth and Knoche, 2015). For data analysis, the cumulative frequency of the number of fruit cracked was plotted against cumulative water uptake. This relationship follows a sigmoidal pattern. A logistic regression model was fitted and the $\mathrm{WU}_{50}$ calculated as the $x$ coordinate at the point of inflection.

Experiments. Potential relationships between the rate of water uptake and the $\mathrm{T}_{50}$ and $\mathrm{WU}_{50}$ were established by quantifying cracking and water uptake in 'Adriana', 'Burlat', 'Dönissens Gelbe', 'Earlise', 'Early Korvic', 'Fabiola', 'Flamengo Srim', 'Gill Peck', 'Hedelfinger', 'Kordia', 'Merchant', 'Querfurther Königskirsche', 'Rainier', 'Regina', 'Sam', 'Samba', 'Schneiders Späte Knorpel', 'Staccato', and 'Sweetheart' sweet cherry.

Cracking following immersion in deionized water and following perfusion through the receptacle was studied in 'Burlat'. In the immersion assay, the rate of water uptake and the time course of cracking were determined and the $T_{50}$ and $\mathrm{WU}_{50}$ calculated as described earlier. The minimum number of replications for the perfusion test was 36 .

The role of microcracks in the cuticle on water uptake and cracking was investigated in 'Summit' sweet cherry fruit. Microcracks were induced by incubating fruit for $24 \mathrm{~h}$ in isotonic PEG 6000 solution. Tonicity was established by water vapor pressure osmometry $\left(\mathrm{VAPRO}^{\circledR} 5520\right.$ and 5600; Wescor, Logan, UT) of juice extracted from fruit of the same batch. Incubating fruit in isotonic PEG 6000 increases the frequency of microcracks in the strained sweet cherry cuticle (Knoche and Peschel, 2006). Thereafter, the time course of cracking following incubation in water, the rate of water uptake, and cracking following perfusion was determined as described earlier. Fruit not incubated in PEG 6000 served as control. The minimum number of replicates for the perfusion test was 39 .

The effect of fruit surface wetness during perfusion was determined in 'Summit'. Fruit was perfused in air and also in a PEG 6000 solution that was isotonic to the fruit's own juice. The minimum number of replicates was 36. For comparison, the $\mathrm{WU}_{50}$ was determined on fruit from the same batch following incubation.

The effect of water uptake along the pedicel/fruit junction was studied in 'Samba', 'Sam', 'Burlat', and 'Regina'. The pedicel was cut to a length of $5 \mathrm{~mm}$ and left open or sealed using a fast-curing silicone (SE 9186, Dow Corning, Midland, MI). 
The silicone was allowed to cure for $\approx 1 \mathrm{~h}$. Time courses of cracking and water uptake were established and the $\mathrm{T}_{50}$ and $\mathrm{WU}_{50}$ calculated.

The effect of simulated skin defects on water uptake and cracking was studied in 'Early Korvic'. Skin defects were simulated by manually puncturing the fruit skin in the cheek region using a double-edged blade. Depth and width of the cuts were $0.8 \times 0.8,2.1 \times 1.7$, and $3.6 \times 2.6 \mathrm{~mm}$. Fruit having an intact skin served as control. Subsequently, water uptake and cracking were determined and the $\mathrm{T}_{50}$ and $\mathrm{WU}_{50}$ calculated as described earlier.

The effect of a nonintact cuticle on water uptake and cracking was investigated in 'Kordia'. A circular area, $\approx 5 \mathrm{~mm}$ in diameter, on the cuticle of the cheek or around the stylar scar region was abraded using abrasive paper (K240; Emil Lux, Wermelskirchen, Germany). Unabraded fruit served as control. Time courses of cracking and water uptake were established and the $\mathrm{T}_{50}$ and $\mathrm{WU}_{50}$ calculated.

The effect of manipulating the fruit water balance by transpiration was investigated in 'Early Korvic'. The pedicel/ fruit junction was sealed using a fast-curing silicone (SE 9186). The silicone was allowed to cure for $\approx 1 \mathrm{~h}$. After curing, fruit were held for $48 \mathrm{~h}$ above water in polyethylene boxes [100\% relative humidity $(\mathrm{RH})]$ or above saturated slurries of $\mathrm{NaCl}[75 \%$ $\mathrm{RH}$ (Wexler, 1995)] or $\mathrm{CaCl}_{2}$ [28\% RH (Wexler, 1995)]. The amounts of water transpired were determined gravimetrically. Thereafter, the time course of cracking and water uptake were quantified and the $\mathrm{T}_{50}$ and $\mathrm{WU}_{50}$ calculated.

The effect of partial wetting of the fruit surface was quantified in 'Sam'. Fruit was incubated with their stylar ends immersed in deionized water in multiwell plates (well diameter $24 \mathrm{~mm}$ ), whereas the skin in the equatorial plane and the stem end were exposed to air of different RHs by placing the multiwell plates in polyethylene boxes above dry silica gel $(0 \% \mathrm{RH})$, saturated slurries of $\mathrm{CaCl}_{2}$ [28\% RH (Wexler, 1995)] or $\mathrm{NaCl}$ [ $75 \% \mathrm{RH}$ (Wexler, 1995)], or above pure water $(100 \%$ $\mathrm{RH})$. The net change in mass was quantified gravimetrically. Cracking was determined by regular visual inspection and the $\mathrm{T}_{50}$ and $\mathrm{WU}_{50}$ calculated. The number of replicates was 10 .

Data ANALYSIs. Data are presented as means \pm SE. Where error bars are not visible in a graph, they are smaller than the plotting symbols or data for individual fruit are shown (Fig. 2B). Data on rates of water uptake were log transformed before analysis of variance (ANOVA). Data were examined using Student's $t$ test, ANOVA, or regression analysis. Pairwise comparisons of treatment means with the nontreated controls were carried out using Dunnett's test or Tukey's Studentised range test at $P \leq 0.05$ (package multcomp 1.3-1, procedure glht, R version 3.0.2; R Foundation for Statistical Computing, Vienna, Austria). Regression analysis was conducted using $R$ version 3.0.2 and SigmaPlot (version 12.5; Systat Software, San Jose, CA). The significances of coefficients of correlation $(r)$ and of determination $\left(r^{2}\right)$ at $P \leq 0.05,0.01$, and 0.001 are indicated by $*, * *$, and $* * *$, respectively.

\section{Results}

Incubating sweet cherry fruit in water resulted in rapid fruit cracking. The time to $50 \%$ cracking $\left(\mathrm{T}_{50}\right)$ averaged $7.5 \pm 1.3 \mathrm{~h}$ for 19 different cultivars with considerable variability between cultivars (range 1.5 to $18.6 \mathrm{~h} \mathrm{~T}_{50}$ ). By $48 \mathrm{~h}$ of incubation, most fruit had cracked (Fig. 1A). Expressing cracking as a function
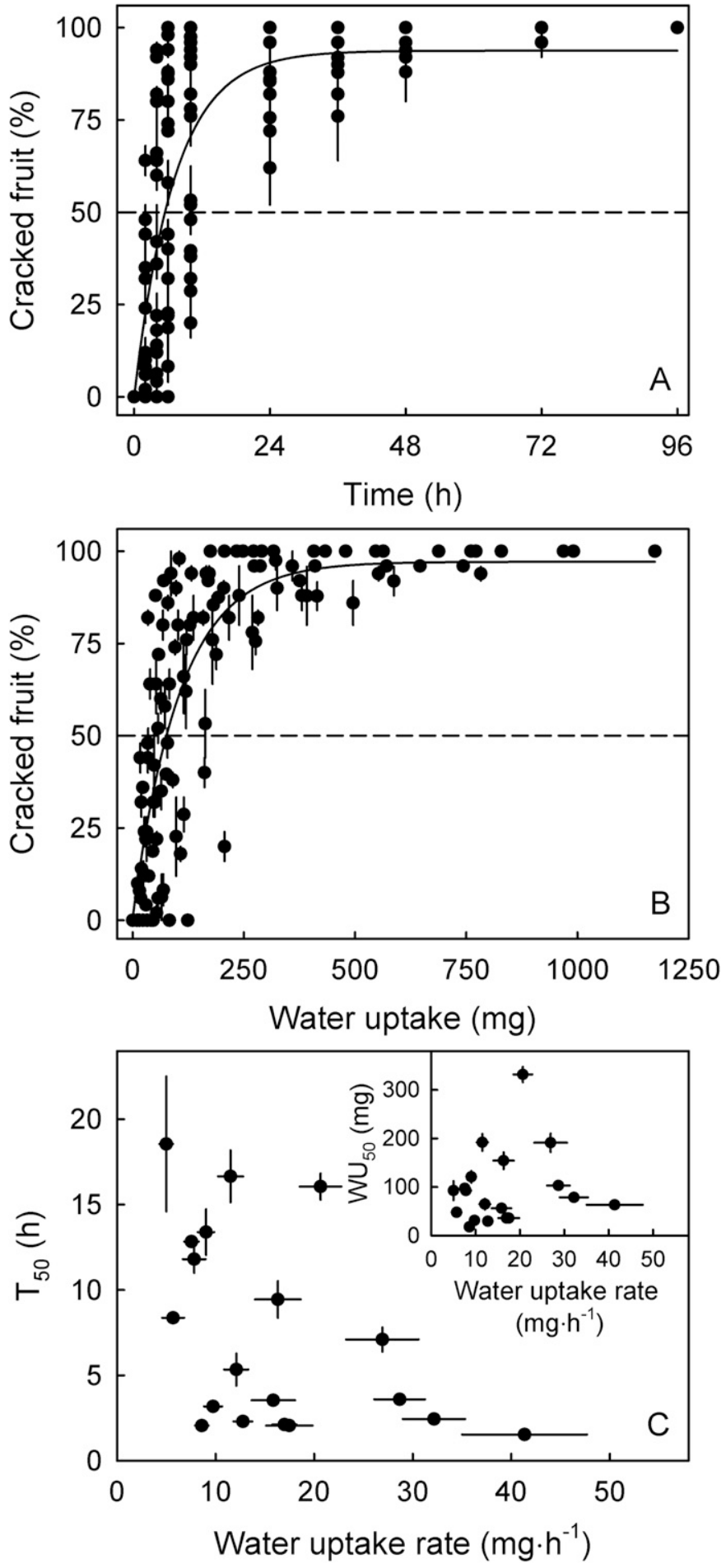

Fig. 1. (A) Time course of cracking of sweet cherry fruit. Data points represent fruit from 19 cultivars. The regression equation was: cracked fruit $(\%)=$ $-29173.3+[29267.1 /(1+\exp \{-[$ time $($ h) -40.9$) / 7.1]\})], r^{2}=0.68^{* * *}$. (B) Cracking of sweet cherry fruit expressed as a function of water uptake. The regression equation was: cracked fruit $(\%)=-21685.4+[21782.6 /(1+\exp$ $\{-[$ uptake $(\mathrm{mg})+572.3] / 105.7\})], r^{2}=0.74 * * *$. (C) Relationship between the time to $50 \%$ cracking $\left[\mathrm{T}_{50}\right.$ (main graph) $]$ or the amount of water taken up at $50 \%$ cracking [ $\mathrm{WU}_{50}$ (inset)], and the rate of water uptake. Data symbols represent individual sweet cherry cultivars.

of water uptake slightly reduced the variability $\left(r^{2}=0.74 * * *\right.$ vs. $r^{2}=0.68^{* * *}$ ) for the relationships with water uptake and time (Fig. 1A and 1B). There was no genotype that stood out as 

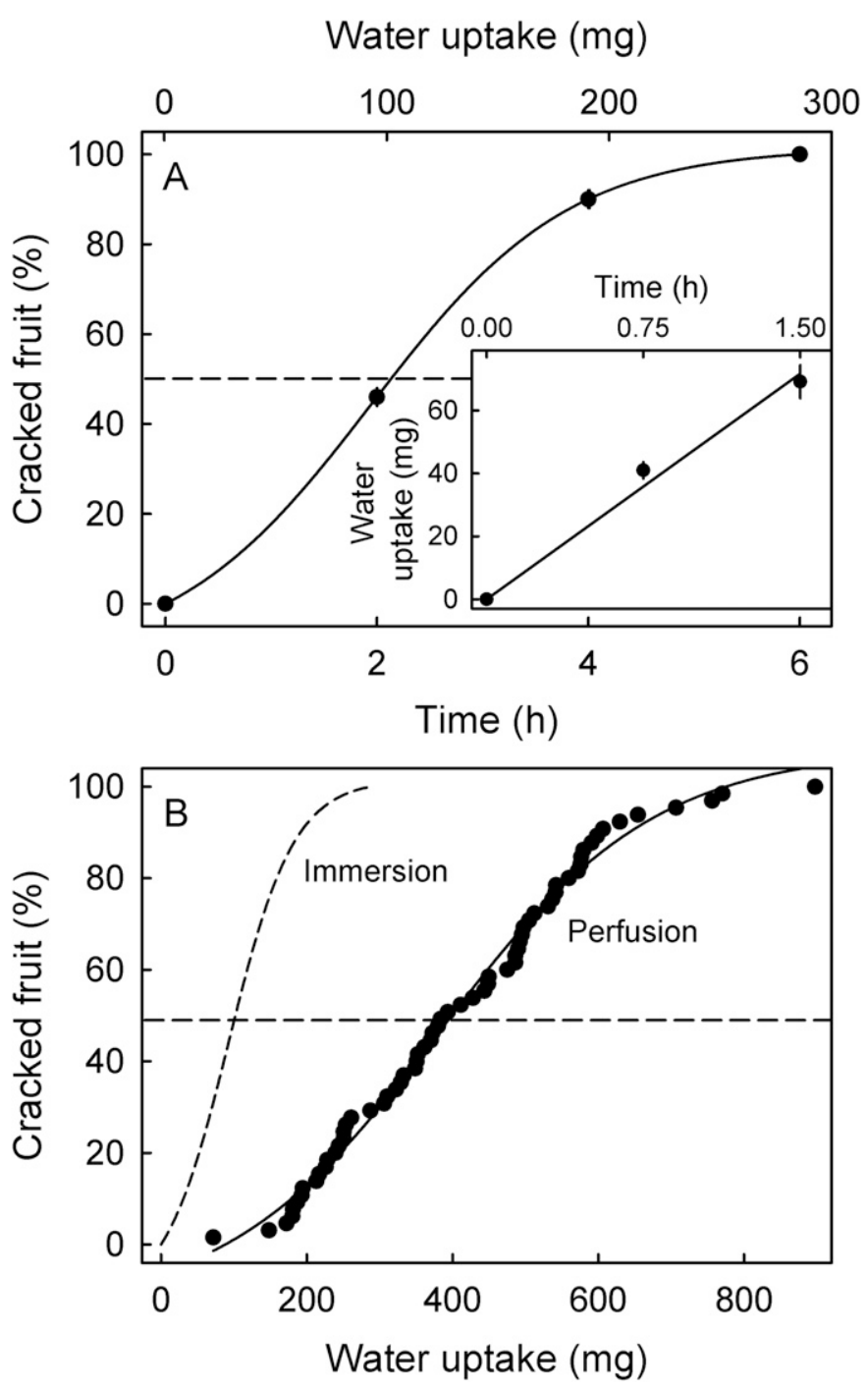

Fig. 2. (A) Time course of water uptake (inset) and cracking when incubating sweet cherry fruit in deionized water (main graph). (B) Cracking as a function of the amount of water perfused into fruit of the same batch. The dashed horizontal lines indicate $50 \%$ cracking. The $x$ coordinates of the intercept between the sigmoid regression line and the $50 \%$ line represent the time to $50 \%$ cracking $\left[\mathrm{T}_{50}(\mathbf{A})\right]$ or the water uptake at 50\% cracking $\left[\mathrm{WU}_{50}(\mathbf{A}\right.$ and $\mathbf{B})$ ]. Dashed line in $\mathbf{B}$ represents the sigmoidal regression line from $\mathbf{A}$ redrawn on the $x$ axis scale of $\mathbf{B}$. having fruit exhibiting a low percentage of cracking despite a long incubation and/or a high water uptake rate. Across cultivars, the amount of water taken up at $50 \%$ cracking $\left(\mathrm{WU}_{50}\right)$ averaged $96.5 \pm 17.6 \mathrm{mg}$ (range from 17.7 to $331.5 \mathrm{mg}$ among cultivars). When expressed as the percentage increase in mass the $\mathrm{WU}_{50}$ averaged $1.0 \% \pm 0.2 \%$ (range from $0.1 \%$ to $4.1 \%$ ). There was no correlation between either the $\mathrm{T}_{50}$, the $\mathrm{WU}_{50}$, or the percentage increase in mass and the rate of water uptake (Fig. 1C). Also, there was no significant relationship between the $\mathrm{T}_{50}(r=0.58)$ and only a weak relationship between the $\mathrm{WU}_{50}\left(r=0.80^{*}\right)$ for 8 of the 19 cultivars that were tested in two consecutive seasons (data not shown).

For an individual genotype, cracking often followed a sigmoidal pattern with time and (at a constant rate of uptake) also with the amount of water taken up (Fig. 2A). For 'Burlat' the $\mathrm{T}_{50}$ and $\mathrm{WU}_{50}$ were $2.1 \pm 0.1 \mathrm{~h}$ and $102.6 \pm 4.0 \mathrm{mg}$, respectively. After $6 \mathrm{~h}$ and $287 \mathrm{mg}$ of water uptake all fruit had cracked (Fig. 2A). When fruit from the same batch was perfused with water, the percentage of cracked fruit also increased in a sigmoidal pattern with water uptake. The $\mathrm{WU}_{50}$ on perfusion, however, was $397.6 \mathrm{mg}$ and thus, was 3.9 times higher than in the immersion assay (Fig. 2B).

Pretreating fruit by incubation in isotonic PEG 6000 for $24 \mathrm{~h}$ resulted in an increased rate of water uptake during subsequent incubation in water as compared with fruit without such pretreatment (Table 1). The $\mathrm{T}_{50}$ was lower for fruit incubated in PEG 6000 , but the $\mathrm{WU}_{50}$ remained constant. However, perfusing fruit from the same batch yielded a $\mathrm{WU}_{50} \approx 38$ times higher than in the incubation assays. There was only a marginal effect on the $\mathrm{WU}_{50}$ in perfusion when fruit were pretreated by incubation in isotonic PEG 6000 (Table 1).

The difference between the $\mathrm{WU}_{50}$ determined in the incubation and perfusion assays was not related to the presence of water on the surface (Table 2). When the fruit surface was wetted during perfusion, the $\mathrm{WU}_{50}$ was almost identical to that when dry fruit were perfused (Table 2). Again, the $\mathrm{WU}_{50}$ was markedly higher in perfusion than in immersion assays.

Water uptake differed markedly between cultivars (Table 3 ). Sealing the pedicel/fruit junction consistently decreased the rate of water uptake in all cultivars. Sealing had no effect on the $\mathrm{T}_{50}$, but decreased the $\mathrm{WU}_{50}$.

Simulated skin defects increased the rate of water uptake compared with the intact control. The increase was positively related to the defect size; i.e., depth and width of the cut. The

Table 1. Effect of water uptake on cracking of sweet cherry fruit. Water uptake occurred via the surface during immersion of whole fruit or by perfusion through a hypodermic needle inserted into the fruit. To assess the role of microcracks, fruits were preincubated for $24 \mathrm{~h}$ in isotonic polyethylene glycol (PEG) 6000 solution before immersion. Fruit without preincubation served as control. Cracking was indexed by the time to $50 \%$ cracking $\left(\mathrm{T}_{50}\right)$ and the amount of water taken up for $50 \%$ fruit to crack $\left(\mathrm{WU}_{50}\right)$.

\begin{tabular}{|c|c|c|c|c|c|}
\hline \multirow[b]{2}{*}{ Treatment } & \multirow[b]{2}{*}{ Pretreatment } & \multirow{2}{*}{$\begin{array}{c}\text { Water uptake rate } \\
{\left[\text { mean } \pm \mathrm{SE}\left(\mathrm{mg} \cdot \mathrm{h}^{-1}\right)\right]}\end{array}$} & \multicolumn{3}{|c|}{ Cracking } \\
\hline & & & $\mathrm{T}_{50}[$ mean $\pm \mathrm{SE}(\mathrm{h})]$ & $\mathrm{WU}_{50}[$ mean $\pm \mathrm{SE}(\mathrm{mg})]$ & $\mathrm{WU}_{50}(\%$ of immersion control $)$ \\
\hline \multirow[t]{2}{*}{ Immersion } & Control & $3.5 \pm 0.4^{z}$ & $13.9 \pm 0.1$ & $48.8 \pm 0.4$ & 100 \\
\hline & 24 h PEG 6000 & $5.1 \pm 0.5^{*}$ & $8.7 \pm 1.2$ & $44.7 \pm 6.0$ & 94 \\
\hline \multirow[t]{3}{*}{ Perfusion } & Control & & $0.7^{\mathrm{y}}$ & $1,840.4$ & 3,772 \\
\hline & 24 h PEG 6000 & & $0.6^{\mathrm{y}}$ & $1,706.5$ & 3,497 \\
\hline & Mean $_{\text {Perfusion }}$ & & $0.7^{\mathrm{y}}$ & $1,773.5$ & \\
\hline
\end{tabular}

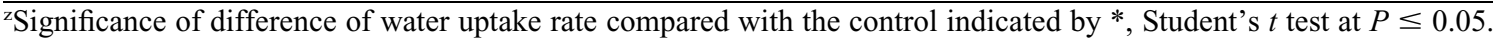

${ }^{y}$ Calculated by dividing the $\mathrm{WU}_{50}$ by the rate of perfusion of $44.9 \mathrm{mg} \cdot \mathrm{min}^{-1}$. 
Table 2. Effect of surface wetness during perfusion on cracking of 'Summit' sweet cherry. Water uptake occurred by perfusion through a hypodermic needle inserted into the fruit. To assess the effect of surface wetness during perfusion, fruit was held with a dry surface in the ambient atmosphere or incubated in isotonic polyethylene glycol (PEG) 6000 solution. Cracking was indexed by the time to 50\% cracking $\left(\mathrm{T}_{50}\right)$ and by the amount of water taken up for $50 \%$ of the fruit to crack $\left(\mathrm{WU}_{50}\right)$. Fruit incubated in deionized water in a classical immersion assay served as control.

\begin{tabular}{llccrc}
\hline & & Water uptake rate & \multicolumn{2}{c}{ Cracking } \\
\cline { 3 - 5 } Treatment & Incubation & {$\left[\right.$ mean $\left.\pm \mathrm{sE}\left(\mathrm{mg} \cdot \mathrm{h}^{-1}\right)\right]$} & $\mathrm{T}_{50}[\mathrm{mean} \pm \mathrm{SE}(\mathrm{h})]$ & $\mathrm{WU}_{50}[\mathrm{mean} \pm \mathrm{SE}(\mathrm{mg})]$ & $\mathrm{WU}_{50}(\%$ of immersion control $)$ \\
\hline Immersion & Water & $9.8 \pm 1.8$ & $7.0 \pm 1.7$ & $68.2 \pm 16.2$ & 100 \\
Perfusion & Air & $0.6^{\mathrm{z}}$ & $0.5^{\mathrm{z}}$ & $1,576.1$ & 2,310 \\
& PEG 6000 & & $0.5^{\mathrm{z}}$ & $1,299.9$ & 1,601 \\
& Mean & & $1,438.0$ & \\
\hline
\end{tabular}

${ }^{\mathrm{z}}$ Calculated by dividing the $\mathrm{WU}_{50}$ by the rate of perfusion of $44.9 \mathrm{mg} \cdot \mathrm{min}^{-1}$.

Table 3. Effect of sealing the pedicel/fruit junction on the rate of water uptake and on cracking of sweet cherry fruit. Sealing the pedicel/fruit junction restricted water uptake to the fruit surface. Cracking was indexed by the time to $50 \%$ cracking $\left(\mathrm{T}_{50}\right)$ and by the amount of water uptake at $50 \%$ fruit cracking $\left(\mathrm{WU}_{50}\right)$.

\begin{tabular}{|c|c|c|c|c|}
\hline \multirow[b]{2}{*}{ Cultivar } & \multirow[b]{2}{*}{ Pedicel/fruit junction } & \multirow[b]{2}{*}{ Water uptake rate $\left[\right.$ mean $\left.\pm \mathrm{SE}\left(\mathrm{mg} \cdot \mathrm{h}^{-1}\right)\right]$} & \multicolumn{2}{|c|}{ Cracking } \\
\hline & & & $\mathrm{T}_{50}[$ mean $\pm \mathrm{SE}(\mathrm{h})]$ & $\mathrm{WU}_{50}[$ mean $\pm \mathrm{SE}(\mathrm{mg})]$ \\
\hline \multirow[t]{2}{*}{ Burlat } & Open & $53.7 \pm 5.8^{\mathrm{z}}$ & $6.3 \pm 0.3$ & $337.8 \pm 17.2$ \\
\hline & Sealed & $10.5 \pm 1.1^{*}$ & $6.9 \pm 1.2$ & $72.7 \pm 12.7$ \\
\hline & Sealed & $7.8 \pm 0.5^{*}$ & $21.3 \pm 6.6$ & $165.3 \pm 50.9$ \\
\hline \multirow[t]{2}{*}{ Sam } & Open & $13.0 \pm 1.3$ & $1.7 \pm 0.5$ & $22.7 \pm 6.6$ \\
\hline & Sealed & $5.2 \pm 0.8^{*}$ & $1.3 \pm 0.1$ & $6.6 \pm 0.5$ \\
\hline Samba & Sealed & $7.8 \pm 0.5^{*}$ & $2.7 \pm 0.2$ & $20.9 \pm 1.7$ \\
\hline \multirow[t]{2}{*}{ Grand mean } & Open & $25.9 \pm 2.8$ & $7.5 \pm 2.5$ & $177.8 \pm 51.6$ \\
\hline & Sealed & $7.3 \pm 0.4^{*}$ & $8.0 \pm 3.3$ & $66.4 \pm 25.5$ \\
\hline
\end{tabular}

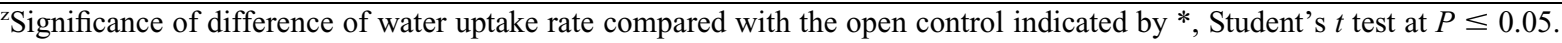

Table 4. Effect of simulated skin defects on the rate of water uptake and cracking of sweet cherry fruit. Skin defects were simulated by puncturing the skin in the cheek region using a double-edged blade. Cracking was indexed by the time to $50 \%$ cracking $\left(\mathrm{T}_{50}\right)$ or by the amount of water taken up at $50 \%$ fruit cracking $\left(\mathrm{WU}_{50}\right)$.

\begin{tabular}{lccr}
\hline & & \multicolumn{2}{c}{ Cracking } \\
\cline { 2 - 4 } Depth $\times$ width of puncture $(\mathrm{mm})$ & Water uptake rate $\left[\mathrm{mean} \pm \mathrm{SE}\left(\mathrm{mg} \cdot \mathrm{h}^{-1}\right)\right]$ & $\mathrm{T}_{50}[\mathrm{mean} \pm \mathrm{SE}(\mathrm{h})]$ & $\mathrm{WU} \mathrm{U}_{50}[\mathrm{mean} \pm \mathrm{SE}(\mathrm{mg})]$ \\
\hline Control & $8.0 \pm 1.2^{\mathrm{z}}$ & $1.8 \pm 0.1$ & $14.4 \pm 0.6$ \\
$0.8 \times 0.8$ & $12.4 \pm 1.9^{*}$ & $1.7 \pm 0.1$ & $20.4 \pm 0.8$ \\
$2.1 \times 1.7$ & $13.1 \pm 1.4^{*}$ & $2.3 \pm 0.6$ & $22.0 \pm 1.8$ \\
$3.6 \times 2.6$ & $14.0 \pm 1.6^{*}$ & $32.3 \pm 8.8$ &
\end{tabular}

${ }^{\mathrm{z}}$ Significance of difference of water uptake rates compared with the control indicated by ${ }^{*}$, Dunnett test at $P \leq 0.05$.

skin defects had only a small effect on the $\mathrm{T}_{50}$, but increased the $\mathrm{WU}_{50}$ relative to the control (Table 4). Furthermore, in only two out of 150 fruit was the site of cracking related to the site of the defect; i.e., the crack only rarely passed through or even close to the defect. In all other cases, the crack location was unrelated to that of the defect. In general, the crack would appear close to the stylar scar (data not shown).

Abrading the cuticle increased the rate of water uptake as compared with the control. It made little difference whether the cuticle was abraded on the cheek or in the stylar scar region (Fig. 3A). Abrading the cuticle on the cheek had little effect on the time course of cracking, compared with the control $\left(\mathrm{T}_{50}: 1.2 \pm 0.1 \mathrm{~h}\right.$ vs. $\left.1.5 \pm 0.3 \mathrm{~h}\right)$, but increased the water uptake, compared with the control $\left(\mathrm{WU}_{50}: 50.4 \pm 6.5 \mathrm{mg}\right.$ vs. $17.6 \pm 3.2 \mathrm{mg})$. Performing the same treatment in the stylar scar region resulted in a 3 -fold increase in the $\mathrm{T}_{50}(3.6 \pm$ $0.0 \mathrm{~h})$ and a nearly 10 -fold increase of the $\mathrm{WU}_{50}(154.8 \pm 1.3 \mathrm{mg})$. Also, the site of cracking changed from cracking primarily in the stylar scar region (control) to cracking in the transition zone between abraded and nonabraded skin, in the shoulder region, or in the cheek region when the stylar scar was abraded.

Manipulating the fruit's water balance by allowing fruit to transpire at different RHs resulted in mass loss of up to $646.7 \pm 26.2$ mg per fruit (Table 5). When fruits were subsequently incubated in deionized water, the $\mathrm{T}_{50}$ and $\mathrm{WU}_{50}$ increased as the water loss due to transpiration increased. Interestingly, the $\mathrm{WU}_{50}$ remained markedly lower than the amount of water previously transpired (Table 5).

Immersing the stylar end of the fruit in water, while exposing the remaining surface to air of $0 \%, 28 \%$, or $75 \% \mathrm{RH}$ resulted in a net loss of water (Table 6). At $100 \% \mathrm{RH}$, the mass of the fruit remained nearly constant. Despite a net loss of water, fruit cracked at the stylar end in all treatments. The $\mathrm{T}_{50}$ was highest after incubation above dry silica gel $(0 \% \mathrm{RH})$ and decreased markedly when RH was increased to $28 \%$ or higher. The negative $\mathrm{WU}_{50}$ values at $28 \% \mathrm{RH}$ and higher indicate fruit cracked despite a net loss of water (Table 6). 

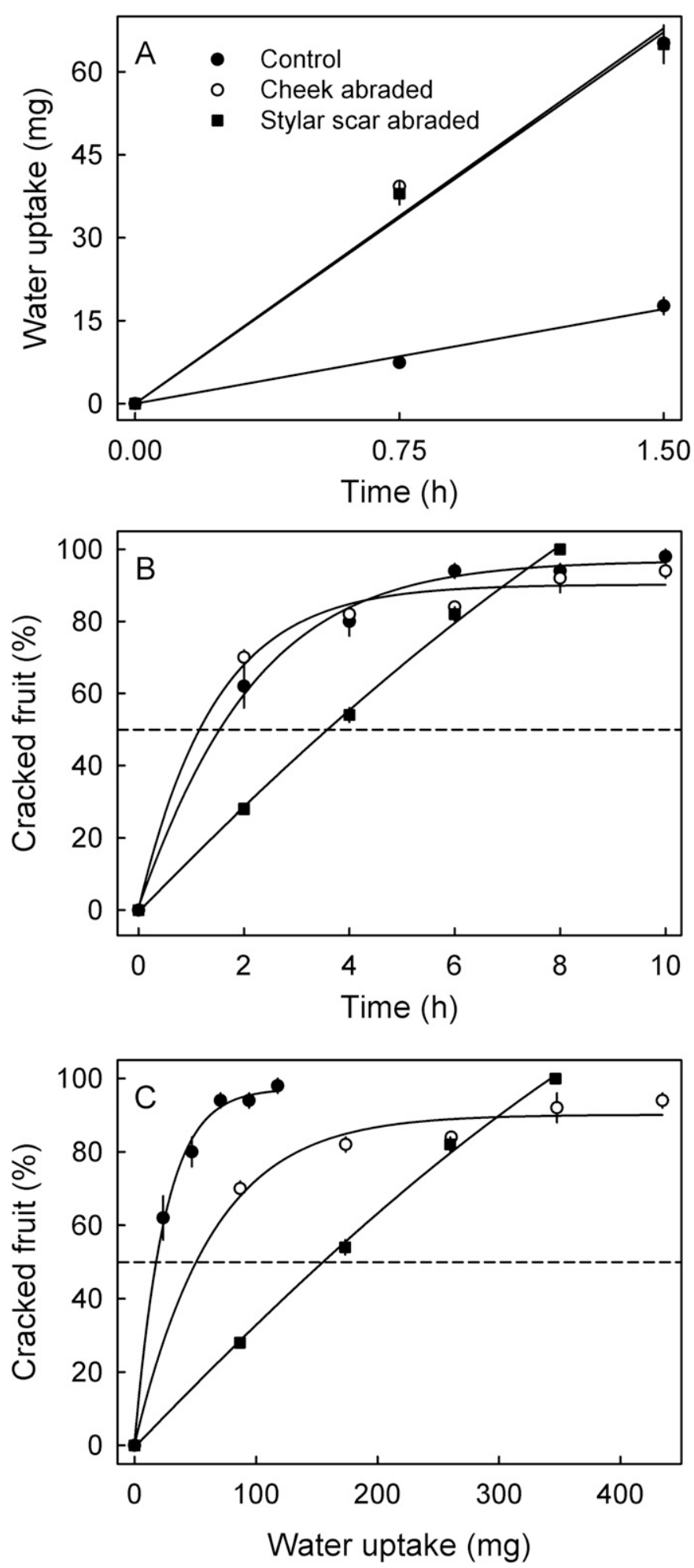

Fig. 3. Effect of abrading the cuticle in the cheek or stylar scar regions on the time course of (A) water uptake and (B) cracking of sweet cherry fruit incubated in deionized water. (C) Percentage of cracked fruit as a function of water uptake. Dashed horizontal line indicates 50\% cracking (B and C).

\section{Discussion}

The results demonstrate that 1) cracking is not a simple function of the amount or of the rate of water uptake and, consequently, 2) the simplistic conceptual model of a sweet cherry being a balloon filled with sugary water held under pressure by a taut skin must be revised.

These conclusions are based on the following arguments. First, the amount of water needed for $50 \%$ cracking $\left(\mathrm{WU}_{50}\right)$ is 3.9- to 38-times larger in the perfusion, compared with in the immersion assays. This difference is not due to the formation of microcracks in the cuticle, nor to the presence of water on the surface during the perfusion period (Tables 1 and 2). Second, although significant water uptake occurred along the pedicel/ fruit junction in this and also in our earlier study [Table 3 (Beyer et al., 2002; Weichert et al., 2004)], this uptake had no effect on the $\mathrm{T}_{50}$. Apparently, the fraction of water taken up along the junction does not contribute to cracking. Thus, the increase in the $\mathrm{WU}_{50}$ must have been an artefact arising from there being a proportion of the water taken up into the fruit that does not contribute to cracking. Third, increasing water uptake by puncturing the fruit surface increased water uptake, but had a surprisingly small effect on the $\mathrm{T}_{50}$ and the $\mathrm{WU}_{50}$ (Table 4). Only in two out of 150 fruit was the site of cracking related to the site of the puncture on the cheek. Similarly, abrading the stylar scar area markedly increased the rate of water uptake, but also the $\mathrm{WU}_{50}$ (Fig. 3). Fourth, water loss due to transpiration did not result in a matching increase in the $\mathrm{WU}_{50}$ (Table 5). In fact, the amount of water lost, exceeded the amount that was subsequently required to cause cracking up to 5-fold. This behavior is quite counterintuitive with the critical turgor hypothesis in mind. Fifth, fruit cracking occurred due to local exposure of the fruit surface to water in this, and also in our earlier study, even when the net water uptake rate is negative [Table 6 (Knoche and Peschel, 2006)]. These data suggest cracking is not a simple function of the amount of water taken up, as would be expected based on the critical turgor model.

The above conclusion is also consistent with a number of puzzling findings reported in the literature. First, the low coefficients of correlation or the lack of correlation between cracking susceptibility and determinants of water uptake such as the fruit size over a range of cultivars (Christensen, 1975; Tucker, 1934; Yamaguchi et al., 2002), the driving force as indexed by the $\psi_{\mathrm{S}}$ of the fruit juice (Christensen, 1972; Moing et al., 2004; Tucker, 1934; Verner and Blodgett, 1931), or the permeance of the fruit surface (Peschel and Knoche, 2012) is in line with the above. Second, the cracking susceptibilities of the same genotypes but assessed in different countries or in different years are often poorly or not significantly correlated [data from Christensen (1996) reanalyzed (M. Knoche, unpublished data)]. Third, water uptake up to the onset of fruit cracking had no detectable effect on turgor (Knoche et al., 2014). Conversely, transpiration had only a small effect on turgor (Knoche et al., 2014). Fourth, water uptake had no effect on fracture strains of the skin in biaxial tensile tests, whereasbased on the critical turgor model - fracture strains would be expected to decrease (Brüggenwirth and Knoche, 2016a). Fifth, there is a more than 20 -fold difference between the critical turgor values reported in the literature [range 2.0 to $3.8 \mathrm{MPa}$ (Measham et al., 2009)] and the turgors obtained by direct measurement at maturity $[<100 \mathrm{kPa}$ (Knoche et al., 2014; Schumann et al., 2014)]. Sixth, biaxial tensile tests of the fruit skin yield fracture strains in the range from $11 \%$ to $38 \%$ (Brüggenwirth and Knoche, 2016a, 2016b; Brüggenwirth et al., 2014). These are markedly higher than those calculated from incubation assays where fruit is immersed in water. Interestingly, the $\mathrm{WU}_{50}$ in the perfusion assay in the present study was 
Table 5. Effect of transpiration on subsequent cracking of sweet cherry fruit when immersed in deionized water. For transpiration, fruit were in air above saturated slurries of $\mathrm{CaCl}_{2}$ [28\% relative humidity $(\mathrm{RH})$ (Wexler, 1995)] or $\mathrm{NaCl}[75 \% \mathrm{RH}$ (Wexler, 1995)], or above water $(\approx 100 \%$ $\mathrm{RH})$ for $48 \mathrm{~h}$ at $22{ }^{\circ} \mathrm{C}$. Cracking was indexed by the time to $50 \%$ cracking $\left(\mathrm{T}_{50}\right)$ and by the amount of water taken up at $50 \%$ cracking $\left(\mathrm{WU} \mathrm{U}_{50}\right)$.

\begin{tabular}{ccccc}
\hline & & \multicolumn{2}{c}{ Cracking } \\
\cline { 3 - 5 } RH $(\%)$ & Transpiration $(\mathrm{mg})$ & Water uptake rate $\left[\mathrm{mean} \pm \mathrm{SE}\left(\mathrm{mg} \cdot \mathrm{h}^{-1}\right)\right]$ & $\mathrm{T}_{50}[\mathrm{mean} \pm \mathrm{SE}(\mathrm{h})]$ & $\mathrm{WU}$ \\
\hline 100 & $11.4 \pm 2.1 \mathrm{c}^{\mathrm{z}}[\mathrm{mean} \pm \mathrm{SE}(\mathrm{mg})]$ \\
75 & $317.5 \pm 18.7 \mathrm{~b}$ & $6.0 \pm 0.7 \mathrm{a}$ & $17.9 \pm 1.6$ & $35.5 \pm 1.3$ \\
28 & $646.7 \pm 26.2 \mathrm{a}$ & $5.9 \pm 0.8 \mathrm{a}$ & $23.5 \pm 3.9$ & $105.7 \pm 9.3$ \\
\hline
\end{tabular}

${ }^{\mathrm{z}}$ Mean separation within columns by Tukey's Studentised range test at $P \leq 0.05$.

Table 6. Effect on cracking of partially wetting the surface of sweet cherry fruit. Fruit were positioned such that their stylar ends were in contact with water whereas the remaining surfaces were in air above dry silica gel $[\approx 0 \%$ relative humidity $(\mathrm{RH})]$ or saturated slurries of $\mathrm{CaCl}_{2}$ [28\% $\mathrm{RH}$ (Wexler, 1995)] or $\mathrm{NaCl}[75 \% \mathrm{RH}$ (Wexler, 1995)], or above water $(100 \% \mathrm{RH})$ at $22{ }^{\circ} \mathrm{C}$. Cracking was indexed by the time required for $50 \%$ fruit to crack $\left(\mathrm{T}_{50}\right)$ or by the amount of water uptake at $50 \%$ fruit cracking $\left(\mathrm{WU}_{50}\right)$. A negative rate of water uptake implies a net water loss.

\begin{tabular}{cccc}
\hline & Water uptake rate & \multicolumn{2}{c}{ Cracking } \\
\cline { 3 - 4 } RH $(\%)$ & {$\left[\right.$ mean $\left.\pm \mathrm{SE}\left(\mathrm{mg} \cdot \mathrm{h}^{-1}\right)\right]$} & $\mathrm{T}_{50}(\mathrm{~h})$ & $\mathrm{WU}_{50}(\mathrm{mg})$ \\
\hline 0 & $-5.9 \pm 0.7 \mathrm{~b}^{\mathrm{z}}$ & 24.6 & -144.9 \\
28 & $-5.3 \pm 1.0 \mathrm{~b}$ & 2.3 & -12.1 \\
75 & $-1.2 \pm 0.2 \mathrm{a}$ & 2.1 & -2.6 \\
100 & $0.7 \pm 0.3 \mathrm{a}$ & 2.1 & 1.5 \\
\hline
\end{tabular}

${ }^{\mathrm{z}}$ Mean separation by Tukey's Studentised range test at $P \leq 0.05$.

up to 38-fold higher than that in the immersion assay. Calculating the strain at fracture for an average $9.6 \pm 0.1 \mathrm{~g}$ fruit yields a fracture strain of $9.1 \% \pm 1.8 \%$ for the perfusion assay, but of only $0.5 \% \pm 0.1 \%$ for the immersion assay. Thus, comparing the skin area increases in the elastometer test and in the perfusion test with those in the immersion test, those in the elastometer and perfusion tests were roughly similar to one another but were more than an order of magnitude larger than those in the immersion test (Brüggenwirth and Knoche, 2016c). Part of this wide discrepancy may be attributable to the higher strain rates occurring in the elastometer and perfusion tests, than in the immersion test (Brüggenwirth and Knoche, 2016c). However, a second factor may be the absence of cell wall swelling when cracking is the result of the mechanical straining of an excised skin or the perfusion of an intact fruit (M. Brüggenwirth, unpublished data). Importantly, if the fruit behaved as predicted by the critical turgor model, we would not expect major differences between fracture strains and fracture pressures determined in biaxial tensile tests, the $\mathrm{WU}_{50}$ measured in perfusion assays and those determined in classical incubation assays. But this is clearly not the case. Thus, we must seek an alternate explanation for rain cracking that accounts for the localized nature of the cracking event.

UNZIPPING THE SKIN-THE ZIPPER MODEL. In the following section, we propose an alternate explanation to account for the localized nature of rain cracking in sweet cherry fruit (and perhaps in some other rain cracking-susceptible species too). We will refer to this model as the zipper model. First, rain cracking is initiated by localized water uptake that occurs through microcracks in the cuticle. Microcracks focus water uptake to a particular region of the epidermis. Second, water is taken up osmotically into the symplast of skin cells and-even more so-that of flesh cells which have a more negative $\psi_{\mathrm{S}}$ (Grimm and Knoche, 2015; Simon, 1977). Unlike the collenchymatype epidermal and hypodermal cells, flesh cells are parenchyma cells that are structurally weak and begin to crack. Third, the bursting of individual flesh cells causes their symplast contents to leak into the apoplast (Herrmann, 2001; Winkler et al., 2015). These contents include malic acid as a major osmolyte. Malic acid is known to disrupt plasma membranes and weaken the cell walls of the adjacent cells causing the bursting to spread (Winkler et al., 2015). Fourth, the continuing loss of osmolytes from symplast to apoplast will cause nearby skin cells to plasmolyse. In turn, plasmolysis is associated with cell wall swelling (Grimm and Knoche, 2015). Also, malic acid is expected to extract $\mathrm{Ca}$ ions from the cell wall which would weaken cross-linking between cell wall constituents and increase swelling (Demarty et al., 1984; Glenn and Poovaiah, 1989; Hepler, 2005). Swelling of cell walls markedly decreases the modulus of elasticity and the fracture pressure (M. Brüggenwirth, unpublished data). In consequence, resistance to strain diminishes and the water uptake continues. The tangential propagation of these processes causes the skin to "unzip", so a cuticular microcrack soon extends into a skin macrocrack in much the same way as a "ladder" will propagate in a piece of fine, knitted fabric. Cuticle and skin are strained (Grimm et al., 2012; Knoche et al., 2004). Upon cracking they will contract causing the crack to gape and to become visible macroscopically.

The zipper model is consistent with the higher frequency of cracking in stem cavity and stylar scar region as compared with the cheek or suture region (Glenn and Poovaiah, 1989; Measham et al., 2009; Sekse, 1998b; Verner and Blodgett, 1931). These regions have a higher frequency of microcracks (Peschel and Knoche, 2005). Microcracks result from a mismatch between surface area expansion and cuticular deposition (Knoche et al., 2004), the small radii of curvature of the fruit surface in these regions (Considine and Brown, 1981), extended periods of surface wetness (Knoche and Peschel, 2006), andpossibly - the mechanical stiffness transition between stylar scar and pedicel vs. skin (A. Lang, personal communication).

The zipper model is also consistent with the well-known engineering phenomenon of cracks focusing stresses at the ends of the crack thereby stimulating crack extension in tangential direction. Extension in radial direction; i.e., toward the pit, would occur by the same mechanism, a stress concentration on the cell walls of epidermal and hypodermal cells that causes the cells to separate and the microcrack to become visible as a macrocrack. Due its low modulus of elasticity (Brüggenwirth et al., 2014), the flesh offers little structural resistance to cracking.

Clearly, some of the links in the causal chain sequence of the zipper model outlined above are more hypothetical than others. 
However, there is sound experimental evidence for most of the links making the zipper model both an attractive and also a logically plausible explanation for the random, unpredictable and local nature of sweet cherry fruit cracking. The zipper model also explains why cracking may still occur despite a fruit suffering an overall net loss of water. This and other recorded behaviors and measured properties do not find ready explanation in the critical turgor hypothesis.

\section{Literature Cited}

Beyer, M., S. Peschel, M. Knoche, and M. Knörgen. 2002. Studies on water transport through the sweet cherry fruit surface: IV. Regions of preferential uptake. HortScience 37:637-641.

Brüggenwirth, M., H. Fricke, and M. Knoche. 2014. Biaxial tensile tests identify epidermis and hypodermis as the main structural elements of sweet cherry skin. Ann. Bot. Plants. doi: 10.1093/ aobpla/plu019.

Brüggenwirth, M. and M. Knoche. 2015. Xylem conductance of sweet cherry pedicels. Trees (Berl.) 29:1851-1860.

Brüggenwirth, M. and M. Knoche. 2016a. Factors affecting mechanical properties of the skin of sweet cherry fruit. J. Amer. Soc. Hort. Sci. 141:45-53.

Brüggenwirth, M. and M. Knoche. 2016b. Mechanical properties of skins of sweet cherry fruit of differing susceptibilities to cracking. J. Amer. Soc. Hort. Sci. 141:162-168.

Brüggenwirth, M. and M. Knoche. 2016c. Time to fracture and fracture strain are negatively related in sweet cherry fruit skin. J. Amer. Soc. Hort. Sci. 141:485-489.

Christensen, J.V. 1972. Cracking in cherries IV. Determination of cracking susceptibility. Acta Agriculturae Scandinavica 22:153162.

Christensen, J.V. 1975. Cracking in cherries VII. Cracking susceptibility in relation to fruit size and firmness. Acta Agriculturae Scandinavica 25:11-13.

Christensen, J.V. 1996. Rain-induced cracking of sweet cherries: Its causes and prevention, p. 297-327. In: A.D. Webster and N.E. Looney (eds.). Cherries: Crop physiology, production and uses. CAB Intl., Wallingford, UK.

Cline, J.A., M. Meland, L. Sekse, and A.D. Webster. 1995. Rain cracking of sweet cherries: II. Influence of rain covers and rootstocks on cracking and fruit quality. Acta Agriculturae Scandinavica Section B Soil Plant Sci. 45:224-230.

Considine, J.A. and P.E. Kriedemann. 1972. Fruit splitting in grapes: Determination of the critical turgor pressure. Austral. J. Agr. Res. 23:17-24.

Considine, J. and K. Brown. 1981. Physical aspects of fruit growth Theoretical analysis of distribution of surface growth forces in fruit in relation to cracking and splitting. Plant Physiol. 68:371-376.

Demarty, M., C. Morvan, and M. Thellier. 1984. Calcium and the cell wall. Plant Cell Environ. 7:441-448.

Glenn, G.M. and B.W. Poovaiah. 1989. Cuticular properties and postharvest calcium applications influence cracking of sweet cherries. J. Amer. Soc. Hort. Sci. 114:781-788.

Grimm, E., S. Peschel, T. Becker, and M. Knoche. 2012. Stress and strain in the sweet cherry skin. J. Amer. Soc. Hort. Sci. 137:383-390. Grimm, E. and M. Knoche. 2015. Sweet cherry skin has a less negative osmotic potential than the flesh. J. Amer. Soc. Hort. Sci. 140:472479.

Hepler, P.K. 2005. Calcium: A central regulator of plant growth and development. Plant Cell 7:2142-2155.

Herrmann, K. 2001. Inhaltsstoffe von Obst und Gemüse. Ulmer, Stuttgart, Germany.
Knoche, M., M. Beyer, S. Peschel, B. Oparlakov, and M.J. Bukovac. 2004. Changes in strain and deposition of cuticle in developing sweet cherry fruit. Physiol. Plant. 120:667-677.

Knoche, M., E. Grimm, and H.J. Schlegel. 2014. Mature sweet cherries have low turgor. J. Amer. Soc. Hort. Sci. 139:3-12.

Knoche, M. and P. Measham. 2016. The permeability concept: A useful tool in analyzing water transport through the sweet cherry fruit surface. Acta Hort. (in press).

Knoche, M. and S. Peschel. 2006. Water on the surface aggravates microscopic cracking of the sweet cherry fruit cuticle. J. Amer. Soc. Hort. Sci. 131:192-200.

Lang, A. and H. Düring. 1990. Grape berry splitting and some mechanical properties of the skin. Vitis 29:61-70.

Measham, P.F., S.A. Bound, A.J. Gracie, and S.J. Wilson. 2009. Incidence and type of cracking in sweet cherry (Prunus avium L.) are affected by genotype and season. Crop Pasture Sci. 60:1002-1008.

Measham, P.F., A.J. Gracie, S.J. Wilson, and S.A. Bound. 2010. Vascular flow of water induces side cracking in sweet cherry (Prunus avium L.). Adv. Hort. Sci. 24:243-248.

Moing, A., C. Renaud, H. Christmann, L. Fouilhaux, Y. Tauzin, and A. Zanetto. 2004. Is there a relation between changes in osmolarity of cherry fruit flesh or skin and fruit cracking susceptibility? J. Amer. Soc. Hort. Sci. 129:635-641.

Peschel, S. and M. Knoche. 2005. Characterization of microcracks in the cuticle of developing sweet cherry fruit. J. Amer. Soc. Hort. Sci. 130:487-495.

Peschel, S. and M. Knoche. 2012. Studies on water transport through the sweet cherry fruit surface: XII. Variation in cuticle properties among cultivars. J. Amer. Soc. Hort. Sci. 137:367-375.

Schumann, C., H.J. Schlegel, E. Grimm, M. Knoche, and A. Lang. 2014. Water potential and its components in developing sweet cherry. J. Amer. Soc. Hort. Sci. 139:349-355.

Sekse, L. 1995a. Fruit cracking in sweet cherries (Prunus avium L.). Some physiological aspects - A mini review. Sci. Hort. 63:135-141. Sekse, L. 1995b. Cuticular fracturing in fruits of sweet cherry (Prunus avium L.) resulting from changing soil water contents. J. Amer. Soc. Hort. Sci. 70:631-635.

Sekse, L. 1998a. Fruit cracking mechanisms in sweet cherries (Prunus avium L-A review. Acta Hort. 468:637-648.

Sekse, L. 1998b. Cuticular fractures in fruits of sweet cherry (Prunus avium L.) affect fruit quality negatively and their development is influenced by cultivar and rootstock. Acta Hort. 468:671-676.

Sekse, L., K.L. Bjerke, and E. Vangdal. 2005. Fruit cracking in sweet cherries-An integrated approach. Acta Hort. 667:471-474.

Simon, E.W. 1977. Leakage from fruit cells in water. J. Expt. Bot. 28:1147-1152.

Tucker, R. 1934. A varietal study of the susceptibility of sweet cherries to cracking. Univ. Idaho Agr. Expt. Sta. Bul. 211.

Verner, L. and E.C. Blodgett. 1931. Physiological studies of the cracking of sweet cherries. Bul. Agr. Expt. Sta. Univ. Idaho 184.

Weichert, H., C. von Jagemann, S. Peschel, M. Knoche, D. Neumann, and W. Erfurth. 2004. Studies on water transport through the sweet cherry fruit surface: VIII. Effect of selected cations on water uptake and fruit cracking. J. Amer. Soc. Hort. Sci. 129:781-788.

Wexler, A. 1995. Constant humidity solutions, p. 15-23. In: D.R. Lide (ed.) Handbook of chemistry and physics. 76th ed. CRC Press, Boca Raton, FL.

Winkler, A., M. Ossenbrink, and M. Knoche. 2015. Malic acid promotes cracking of sweet cherry fruit. J. Amer. Soc. Hort. Sci. 140:280-287.

Yamaguchi, M., I. Sato, and M. Ishiguro. 2002. Influences of epidermal cell sizes and flesh firmness on cracking susceptibility in sweet cherry (Prunus avium L.) cultivars and selections. J. Jpn. Soc. Hort. Sci. 71:738-746. 